\title{
STUDY ON INTEGRATED LIQUEFACTION HAZARD MAPPING DEVELOPED BY SPT, CPT, DOWNHOLE AND LPI INDEX
}

\author{
Babak Jamhiri ${ }^{*}$, Mohammad Parsaeimaram ${ }^{2}$ \\ ${ }_{1}^{1}$ Master of Geotechnical Engineering, Department of Civil Engineering, Shahid Chamran University, Ahvaz, Iran \\ ${ }^{2}$ PhD of Earthquake Engineering, Department of Civil Engineering, Shanghai Jiao Tong University, Shanghai, China \\ *Corresponding Author Email: bjamhiri@gmail.com
}

This is an open access article distributed under the Creative Commons Attribution License, which permits unrestricted use, distribution, and reproduction in any medium, provided the original work is properly cited.

\section{ARTICLE DETAILS}

\section{Article History:}

Received 1 January 2019

Accepted 15 February 2019

Available online 20 March 2019

\section{ABSTRACT}

This paper aims to investigate liquefaction hazard assessment criteria available in practice which are obtained by geotechnical tests. In this study, developed indices for evaluation of liquefaction potential of susceptible soils under earthquake excitation were analyzed. From basic physical engineering indices resultant from in-laboratory investigations such as grain size distribution curves to the more sophisticated in-situ tests such as Downhole, standard penetration test (SPT), cone penetration test (CPT) and piezocone modified (CPTu) test, developed criteria were studied. Subsequently, liquefaction potential index (LPI) based-criteria for quantification of relationships among applicable in-situ tests were discussed. Finally, in reference to the data presented in this paper, appropriate methods such as geologic hazard mapping were suggested for further visualizing of coupled analyses with the aim of providing practical instrumentation of geological maps in liquefaction hazard assessment.

\section{KEYWORDS}

liquefaction potential, hazard risk assessment, seismic response, LPI index

\section{INTRODUCTION}

Liquefaction is one of the most vital problems that unsupported soils undergo during the earthquake excitation. When saturated fine granular soils are under seismic loading, the surrounding stress will become zero and the soil acts like a liquid body with no bearing capacity. With the increase of pore pressure and no possible drainage; induced pore pressure is building up and a state of total failure occurs. During earthquake, fine granular soils are the most susceptible soils to liquefaction [1,2]. Although some researches also indicated that saturated silts and clays which behave more fundamentally like sands (sand-like behavior) also could experience liquefaction [3,4].

Considering low to almost zero cohesion in silty sands and lack of a manageable draining system which lead to the highest liquefaction risk potential in sands, there are many methods to evaluate liquefaction potential in places where sand deposits exist; particularly close to rivers and sea sides. But, the important measure after evaluation of liquefaction hazard is to visualize the details as practical as possible so that practitioners could benefit from applying it into their considerations. Thus, to provide practical resources, liquefaction geologic-hazard maps with zonation were developed [5,6]. Liquefaction geologic-hazard maps have been developed for numerous sub regions by micro- zonation of liquefaction hazard based on the severity of liquefaction. The geologic maps help the design professional by delineating locations where liquefaction could pose as a threat and should therefore be considered during construction designs. The maps can also be utilized by local authorities and land use policy makers for urban planning and emergency reaction planning. In order to provide a multi-disciplinary manifestation of liquefaction hazard mapping for practitioners in both geology and earthquake engineering, in this paper different liquefaction criteria and correlated equations are studied with the aim of enlightening procedures available for development of hazard maps. In reference to the common procedures, driven in-situ measuring such as cone penetration test and its modified version with pore water pressure recording (CPTu) and Downhole and soil's engineering physical indices such as PI, LL and grain size distribution curve were investigated and in respect of their individual capacity and reliability the scope of their application by means of LPI index was analyzed and also the most suitable approach for developing hazard maps based on performed tests was reported.

\section{MATERIAL AND METHODS}

Aiming at instrumenting available methods among in-situ and inlaboratory geotechnical tests for liquefaction resistance assessment, in the present study preliminary liquefaction investigations which were developed from simple soil's physical indices were studied. In the same vein, methods which were developed based on that in-laboratory physical indices were studied by highlighting the advantage and shortcomings of each method.

In the light of general knowledge obtained by lab tests, more sophisticated in-situ tests such as CPT, SPT, Downhole were analyzed and each test's capability in producing reliable results were identified. According to the performance of each in-situ test, various driven LPI indices were implemented in practical application with the goal of finding a better option for mapping geological hazard maps.

\section{DISCUSSIONS}

3. 1 Developed Liquefaction criteria based on physical engineering indices

As majority of liquefaction assessment criteria, are dependent partially or 
even totally on physical engineering indices of soil it should be worthwhile to first present a brief review of available procedures. With Kocaeli earthquake (Turkey) and Chi-Chi earthquake (Taiwan), liquefaction led to devastation of many infrastructures and caused numerous deaths. An important observation in those areas was that in many cases liquefaction failures (partial settlement and partial loading failure) occurred in places where the majority of soil aggregate distribution and strata were of fine soils. According to several researchers, liquefaction resistance of silty clay soils is mainly dependent on PI index of soils [7]. Considering previous liquefaction incidents there are various common criteria for evaluation of liquefaction susceptibility in fine granular soils including Wang criterion $[8,9]$.
In the light of Wang studies, it is proven that liquefaction potential is controlled by aggregate size, liquid limit (LL) and soil moisture content. Modified Chinese liquefaction criterion based on the 1975 Haichang and 1976 Tangshan earthquakes which was then modified by a researcher is the most common used criterion in practice over the past 30 years [10]. According to the Chinese criterion (Figure 1), three conditions must exist simultaneously so that the fine soil sustains liquefaction such as it must include less than $15 \%$ clay fraction (finer than $0.005 \mathrm{~mm}$ ); liquid limit (LL) with less than $35 \%$ and in-situ water content higher than $90 \%$ of liquid limit. It should be noted that Polito and Martin, concluded that indiscriminate use of the modified Chinese criterion as a substitute for laboratory and in-situ testing should be avoided [11].

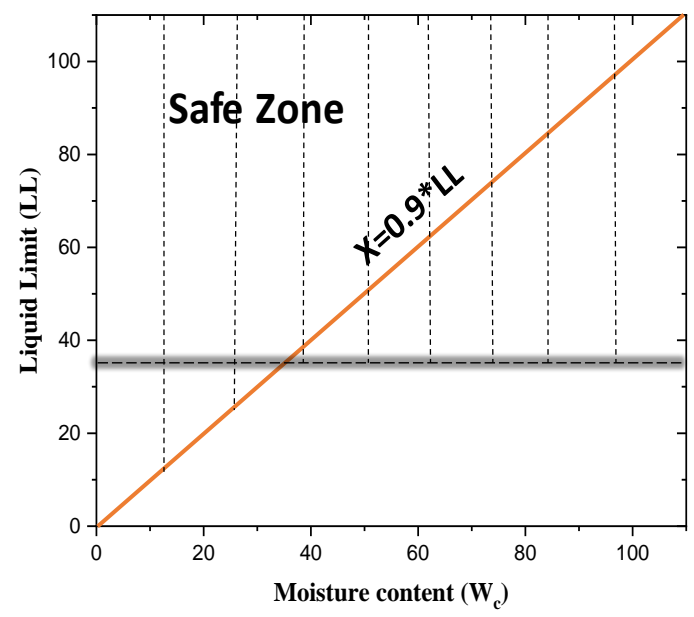

Figure 1: Safe liquefaction area in fine soils according to Wang criterion

According to a scholar who further investigated reported results by another scholar, if soil fraction less than $0.002 \mathrm{~mm}$ is equal or higher than 10 percent and concurrently its liquid limit is higher or equal to 32 percent, the soil is not prone to liquefaction.

A scholar criterion was a complete empirical conclusion drawn by contradictory observations between modified Chinese criterion estimations and real liquefaction incidents in Kocaeli earthquake (Turkey) and Chi-Chi earthquake Taiwan where according to modified Chinese criterion the zone was predicted to be safe. Further investigations by a group of researchers revealed that the part related to explaining clay fraction in modified Chinese criterion is poor and amount of clay fraction is less important than the total amount of fine portion's effect in plastic index, PI [12]. In addition, as can be seen in (Figure 2), they concluded that liquefaction could happen in soils with clay fraction between 10 to 15 percent and soils which are not fall into zone A and zone B are not susceptible to liquefaction and can be handled as safe zones.

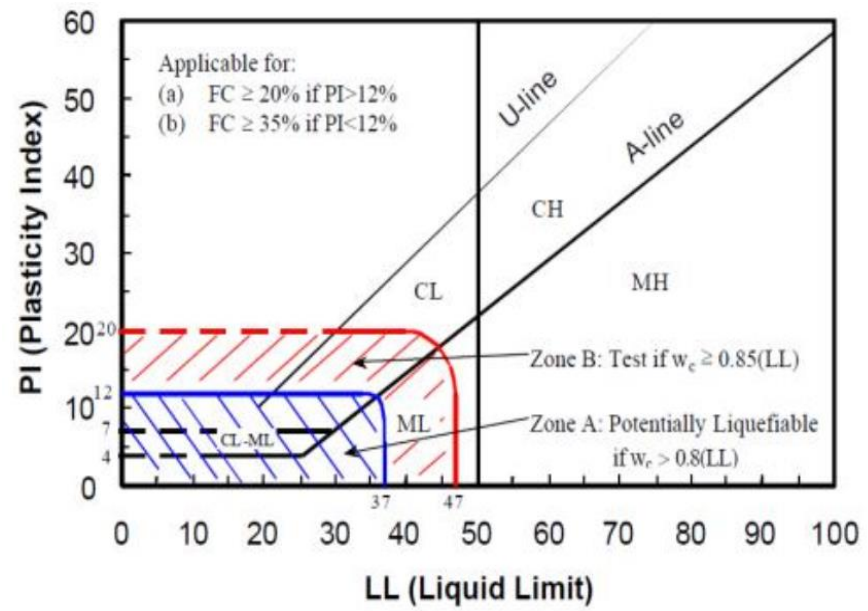

Figure 2: Seed et al. modified liquefaction potential criterion based on modified Chinese criterion developed by Wang

\subsection{Liquefaction potential criteria based on SPT test}

One of the most common practices for estimating soil susceptibility to liquefaction is the number of NSPT blows obtained from standard penetration test (SPT). The benefits of instrumenting SPT test to evaluate liquefaction potential is that the test's capability of recording soil parameters in undrained condition which is as close to real situation during earthquake excitation.
The original simplified procedure for evaluating liquefaction potential of soils was proposed by employing the SPT blow counts correlated with a parameter representing the seismic loading on the soil, called cyclic stress ratio (CSR) [13]. Early works done by a researcher was mainly focusing on developing a standardized guideline which can then be used as a basis for evaluating liquefaction resistance based on application of CSR and penetration resistance counts by SPT as following: 
$C S R_{\text {peak }}=\left(\frac{a_{\max }}{g}\right) \times\left(\frac{\sigma_{v}}{\sigma_{v}^{\prime}}\right) \times\left(r_{d}\right)$

where $a_{\text {max }}$ is horizontal ground surface acceleration; $\mathrm{g}$ is acceleration of gravity; $\sigma_{v}$ is total vertical stress; $\sigma_{v}^{\prime}$ is effective normal stress and $r_{\mathrm{d}}$ is non-linear shear mass participation coefficient. Sound performance of Eq. (1) requires the calculation of the cyclic stress ratio (CSR), and more importantly cyclic resistance ratio (CRR) which is the normalized cyclic shear stress that causes liquefaction. To establish a factor of safety for liquefaction resistance, a ratio between the cyclic resistance ratio and the cyclic stress ratio generated by the earthquake ground motions at the site should be available to instrument the SPT blow counts. Generally, if CSR value is greater than the value of CRR, liquefaction can happen. Although SPT is the most available procedure in practice; it has some drawbacks too. The parameter $\left(\mathrm{N}_{60}\right)$ is strongly affected by grain size distribution. As a consequence, a same value for $\left(\mathrm{N}_{60}\right)$ refers to a fine sand with high relative density, whereas simultaneously it could refer to a very low relative density for a medium coarse sand.

\subsection{Developed Liquefaction criteria based on CPT and CPTu results}

The cone penetration test (CPT) has recently become the most widely used and accepted test methods for determining geotechnical soil properties. A previous researcher compared calculated liquefaction potential against field performance at 19 sites and concluded that the CPT data interpretation correctly predicted the occurrence or nonoccurrence of liquefaction with $>85 \%$ reliability [14]. CPT's capabilities in measuring cone's resistance, membrane resistance, sleeve friction, pore water pressure recording (with its derivative, $\mathrm{CPTu}$ ) and also repeatability and reliability of measured data; produced a proper analysis index to predict liquefaction potential. Another researcher introduced soil behavior index $I_{\mathrm{c}}$ to predict soil liquefaction potential by CPT testing as following [15]:

$$
I_{c}=\left[(3.47-\log Q)^{2}+(1.22+\log F)^{2}\right]^{n}, F=\frac{f_{s}}{q_{c}-\sigma_{v o}} \times 100 \%
$$

where $Q$ is normalized cone penetration resistance and based on a simple linear stress the exponent $n$ is typically equal to 1.0 and $F$ is the normalized friction ratio. According to Eq. (2) a particular soil behavior-type chart was developed and as can be seen in (Figure 3), soil types are characterized in 9 zones as 1 , sensitive, fine grained; 2 , peats; 3 , silty clay to clay; 4 , clayey silt to silty clay; 5 , silty sand to sandy silt; 6 , clean sand to silty sand; 7 , gravelly sand to dense sand; 8 , very stiff sand to clayey sand (heavily over consolidated or naturally cemented); 9, very stiff, fine grained (heavily over consolidated or naturally cemented). It should be noted, if the $I_{c}$ become less than 2.6 the studied soil is characterized as clay and due to high plasticity, it is not susceptible to liquefaction. But if the $I_{c}$ is more than 2.6 and normalized friction ratio, $F$ is less than 1.0 and soil is then categorized as very susceptible.

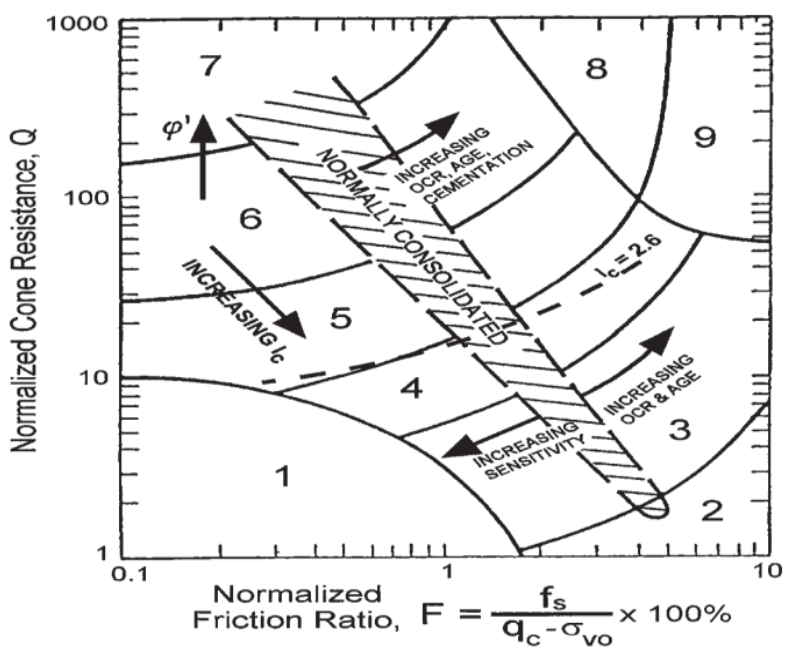

Figure 3: Normalized CPT soil behavior type chart, as proposed by (Robertson and Wride [15])

Another method for analyzing CPT data is by incorporating CRR which according to this method, resistance to cyclic loading is usually represented in terms of a cyclic stress ratio that causes cyclic liquefaction. Although, based on modified Chinese criterion soils which fall into zone 1 of (Figure 3) are not technically susceptible to liquefaction, but such sensitive soils may experience softening and strength deprivation during seismic cyclic loading. Still, the developed chart by a recent scholar lacks a zone which represents the behavior of total clean sand where the $I_{c}$ is more than 2.6 thus a normalized penetration resistance $\left(q_{\mathrm{c} 1 \mathrm{~N}}\right)$ for silty sands is corrected to an equivalent clean sand value $\left(q_{\mathrm{c} 1 \mathrm{~N}}\right)$, as following relation:

$$
\left(q_{c 1 N}\right)=K_{c} q_{1 N}
$$

where $K_{c}$ is the correction factor for grain characteristics and is defined by the following equation:

$$
\begin{aligned}
& \text { for } I_{c} \leq 1.64 K_{c}=1.0 \\
& \text { for } I_{c}>1.64 K_{c}=-0.403 I_{c}^{4}+5.581 I_{c}^{3}-21.63 I_{c}^{2}+33.75 I_{c}-17.88
\end{aligned}
$$

By calculating the data obtained by the Eq. (4), a researcher defined a $K_{\mathrm{c}}$ curve for determination of clean-sand's equivalent CPT tip resistance as can be seen in (Figure 4).

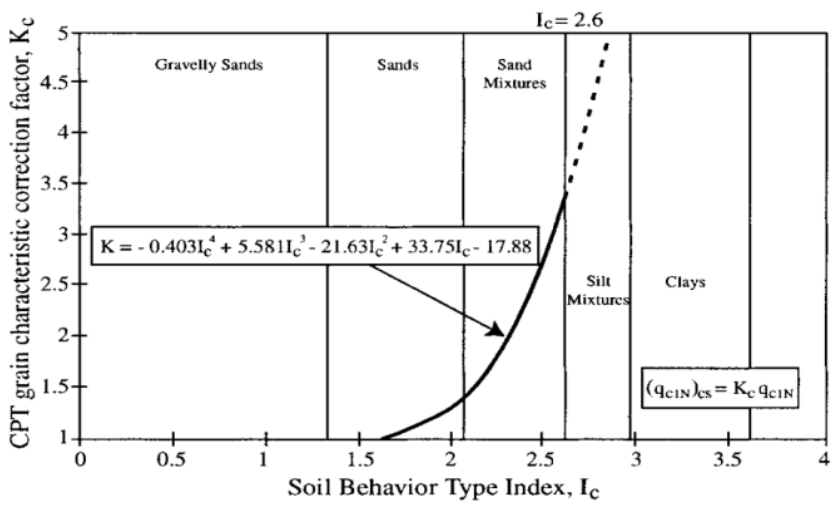

Figure 4: $\mathrm{K}_{\mathrm{c}}$ curve interpolation to determine corrected CPT tip resistance for equivalent clean sand based on different granular soil characterization Robertson and Wride [15] 
Also, the other type of CPT test, CPTu, which is the modified version of CPT and includes a piezocone apparatus at the tip of the cone is also in practice where undrained shear strength of clayey soils due to the measurement of pore water pressure is corrected based on the cone tip resistance. CPTu reflect a true reliable characteristics of soil strength [16]. A common CPTubased liquefaction prediction method consists of the researcher's methods where the ratio of CSR to CRR is multiplied to the magnitude scaling factor, $M S F$, as given in following equation [17]:

$$
F o S=\left(\frac{C R R}{C S R}\right) \times M S F
$$

where, $F o S=$ factor of safety and if the safety factor is more than 1.0 , the liquefaction occurrence is in overall not expected. In reference, a previous researcher developed a soil profiling method by investigating a database

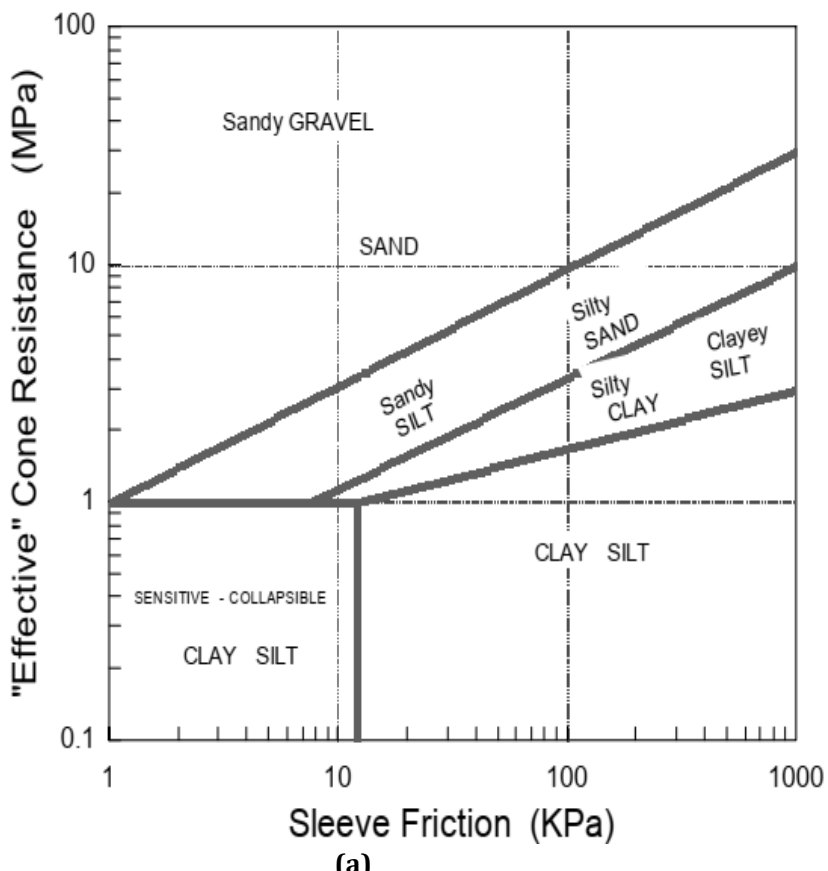

(a) consisting of CPT and CPTu data associated with the results of borehole testing and routine soil physical characteristics $[18,19]$. Although, the database does not contain cases with cemented soils or very stiff clays, and for this reason, no envelopes for such soil types are included in this characterizing chart (See Figure 5.a). A researcher further elaborated another researcher characterizing charts and incorporated those data with case histories and Robertson correction index chart to develop a chart with soils being categorized into zones that can readily be used for liquefaction evaluation of saturated soils [20]. In other words, when using Robertson chart or Eslami Fellenius charts, if CPTu data envelopes associated with for example a saturated granular soil are falling in the zone highlighted in (Figure 5.b), this soil has a high potential risk for liquefaction. It should be pointed out that, proposed approach in Eslami and Fellenius chart could predict the liquefaction potential risk of granular soils. Although this does not mean that other CPTu data points which are not located on the suggested zone do not show liquefaction during earthquake ground motion.

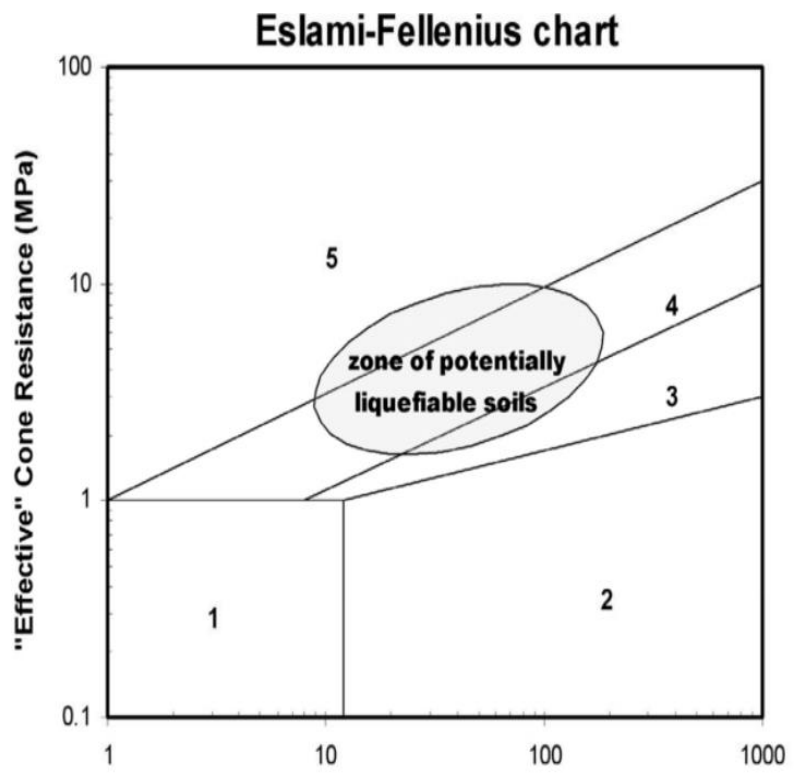

Sleeve Friction $(\mathrm{kPa})$

(b)

Figure 5: a) Eslami and Fellenius [19] characterizing chart as cone sleeve friction and effective cone resistance, b) Ahmadi et al. CPTu zone detecting curve for liquefaction potential assessment

Additionally, as Robertson chart was modified by Eslami and Fellenius characterizing chart, there are still high probability of cases where clayey soil deposits exist in combination with saturated loose sandy soils. Particularly, Eslami and Fellenius charts eliminated clayey soils due to the fact that those soils required very limited conditions for liquefaction while saturated loose sands frequently have showed the highest potential risk for liquefaction.

\subsection{Liquefaction potential criteria based on Downhole test}

Seismic response records obtained by in-situ Downhole tests are a valuable supplement to the laboratory investigation techniques. Particularly, analyses of Downhole seismic array data can provide unique information on undisturbed soil and overall soil shear response without disturbing the substrata if certain measures appropriately be taken by operators. Additionally, over a wide range of loading conditions and cases that are not promptly simulated by in-situ or laboratory examination can be recorded by real time reading of shear wave velocity $\left(V_{S}\right)$ [21]. The use of $V_{\mathrm{S}}$ for determining liquefaction potential is soundly based because both $V_{S}$ and liquefaction resistance ratio are influenced by many of the same factors. Laboratory studies have shown that confining stress, soil gradation and plasticity and void ratio/relative density are the most important factors influencing the variation of shear modulus, or shear wave velocity with shear strain amplitude [22].

Thus, by measuring an equivalent $V_{\mathrm{s}}$ to in-situ small-strain shear-wave velocity measurements, liquefaction potential is predictable. A researcher in reference to shear-wave velocity, proposed a procedure for liquefaction potential prediction which this procedure requires a three step calculation of first, correlated induced cyclic loading on high risk soils and then the CSR value with consideration of stiffness of soil due to overburden stress modified by shear wave velocity and after that the soil resistance to liquefaction in the term of CRR $[23,24]$. Accordingly, CSR is obtained by modifying Eq. (1) as:

$$
C S R=\frac{\tau_{a v}}{\sigma_{v}^{\prime}}=0.65\left(\frac{a_{\max }}{g}\right)\left(\frac{\sigma_{v}}{\sigma_{v}^{\prime}}\right) r_{d}
$$

where in Eq. (6) $\tau_{a v}$ is the average corresponding uniform cyclic shear stress caused by the earthquake and it is assumed to be 0.65 of the maximum induced stress, $a_{\max }$ is the peak horizontal surface ground acceleration, $\mathrm{g}$ is the acceleration of gravity, $\sigma_{v}$ is the initial effective normal stress at any given depth, $\sigma_{v}$ is the total overburden stress at the same depth and $r_{d}$ is a shear stress-reduction coefficient which according to a researcher's suggestion, its proposed relations are summarized in Eq. (7). Additionally, the following equations can be used to estimate average values of $r_{\mathrm{d}}$ based on the studied depth below the ground surface (z) [25]:

$$
\begin{aligned}
& r_{d}=1.0-0.00765 z \text { for } z \leq 9.18 m \\
& r_{d}=1.174-0.0267 z \text { for } 9.15 m<z \leq 23 m
\end{aligned}
$$


Considering that, CRR can be driven as the function of CSR separating liquefaction and no-liquefaction occurrences for a given $V_{s}$ records by the Downhole test, a series of CRR- $V_{s}$ data correlations by multiple regression were presented as fitting curves by a previous researcher for 7.5 Richter's magnitude scale earthquakes as shown in (Figure 6).

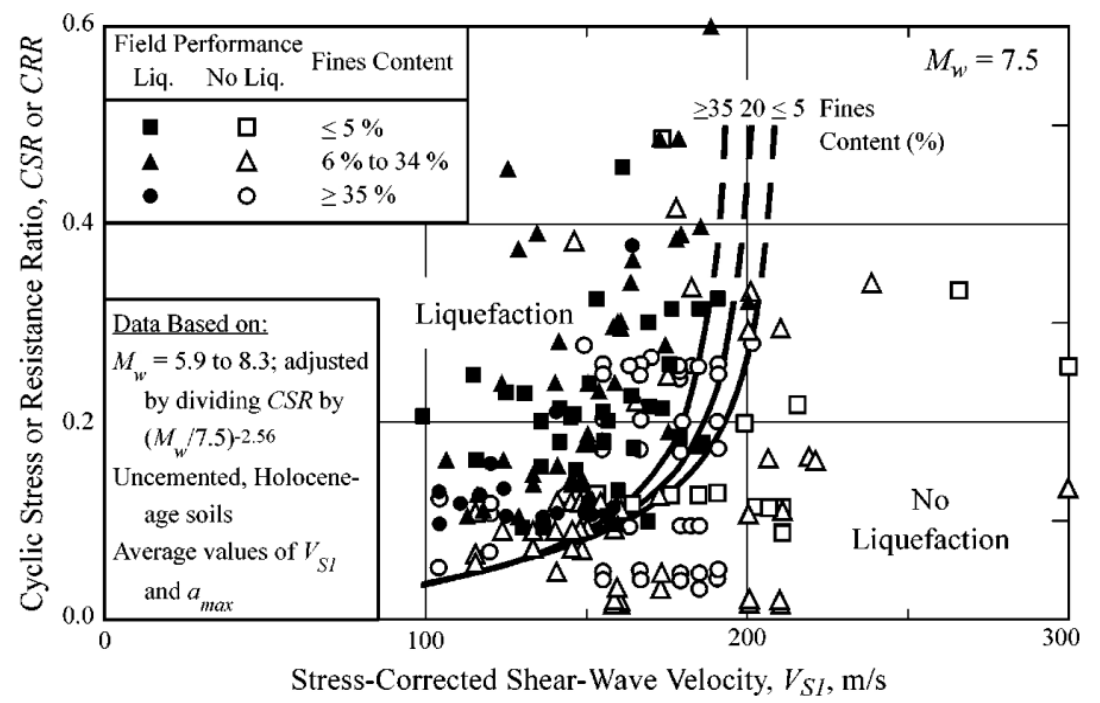

Figure 6: Liquefaction resistance CRR-Vs curves by Andrus and Stokoe [23] for magnitude of 7.5 Richter

In general, traditional Downhole testing is comprising of profiling in 30 to 150-m depth range. As a result, considerably deeper investigations have been required at critical sites such as those associated with underground structures or storage facilities. At these sites, profiling depths have been in the range of 300 to $600 \mathrm{~m}$ or more. This increased profiling depth has required new or improved seismic methods and equipment, or else, postprocessing of the Downhole recordings should compensate for increased signal-to-noise ratios at deeper depths [26].

It should be emphasized that, as previously mentioned by introducing Eq. (5), a key factor in employing CRR- $V_{S}$ liquefaction resistance curves is that the magnitude scaling factor $(M S F)$ is traditionally applied to CRR, rather than CSR, and is equal to 1.0 for earthquakes with a magnitude of 7.5 Richter. For magnitudes other than 7.5 Richter, Youd and Idriss recommended $M S F$ s calculation based on revised $M S F$ developed by a scholar from the following relationship [27]:

$$
M S F=\left(\frac{M_{w}}{7.5}\right)^{-2.56}
$$

where $M_{w}$ is the moment magnitude of earthquake. But, as the majority of

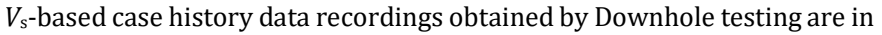
range of 7 to 7.5 on the Richter scale, the difference is negligible. Then, by calculation of CSR value base on the fitting curves and considering the safety factors and keeping in mind that each depth which Downhole testing is done at should be evaluated separately, and by employing engineering judgment; the susceptibility of a certain ground layer is determined as a safety factor scale.

\subsection{Liquefaction evaluation by incorporating CPT and SPT results using LPI index}

Carried observations to assess liquefaction potential by means of CPT and SPT are common in engineering practices. Meanwhile, interpretation of recorded results to serve as efficient as possible is of significant importance. To quantify made observations by in-situ tests, a researcher proposed the LPI index based on Chinese modified criterion to better characterize the damage potential of liquefaction, where LPI is computed as [28]:

$$
L P I=\int_{0}^{20 m} F \times w(z) d z
$$

In Eq. (9), $F$ is the function of a factor of safety (FoS) which is obtained from a simplified liquefaction evaluation procedure and $W(z)$ is depthweighting function calculated in meters below the ground level. While, LPI index does not precisely segregate liquefied and non-liquefied soils, liquefaction potential observations are generally associated with higher LPI values whereas sites without liquefaction manifestations are generally associated with lower LPI values. Many Researchers classify CPT and SPT readings in the term of a LPI range as shown in Table 1. But, as can be seen in Table 1, still a reliable unified range to cover all possible conditions where soil experiences seismic shearing does not exist. Noticeably, Interpretation of experimental readings of in-situ tests is dependent to each post-earthquake database which is then used to drive an specific criterion, given that in such cases even the soil type of investigated location has a great influence on the proposed criterion as for example the Iwasaki criterion is more suited to interpret SPT blows in sand deposits [29].

\begin{tabular}{|c|c|c|c|c|}
\hline Research & Test/Instrumentation method & Location reference & $\begin{array}{l}\text { Severe liquefaction } \\
\text { potential }\end{array}$ & $\begin{array}{l}\text { Minor liquefaction } \\
\text { potential }\end{array}$ \\
\hline Iwasaki criterion 1978 & $\begin{array}{l}\text { SPT-Based utilizing simplified Chinese } \\
\text { method }\end{array}$ & Japan & LPI $>15$ & LPI $>5$ \\
\hline Youd and Idriss 2001 & $\begin{array}{c}\text { SPT-Based utilizing Robertson and } \\
\text { Wride (1998) }\end{array}$ & $\begin{array}{l}\text { Taiwan, Turkey, } \\
\text { Greece }\end{array}$ & LPI $>38$ & LPI $>14$ \\
\hline Toprak and Holzer 2003 & $\begin{array}{l}\text { CPT-Based utilizing Robertson and } \\
\text { Wride method }\end{array}$ & State of California & LPI $>10$ & LPI $>3$ \\
\hline Lee et al. 2004 & $\begin{array}{c}\text { CPT-Based utilizing Robertson and } \\
\text { Wride (1998) }\end{array}$ & Taiwan & LPI $>21$ & LPI $>13$ \\
\hline Papathanassiou 2008 & $\begin{array}{l}\text { SPT-Based box-whisker plot of grouped } \\
\text { case histories based on degree of } \\
\text { severity }\end{array}$ & $\begin{array}{l}\text { Taiwan, Turkey, } \\
\text { Greece }\end{array}$ & LPI $>32$ & LPI $>19$ \\
\hline
\end{tabular}

Table 1: Liquefaction potential indices (LPI) developed after SPT and CPT tests 
Another reason for the differences among values in Table 1, is that the evaluation of liquefaction susceptibility of soil layers beside Iwasaki criterion was based on the modified criterion proposed by a researcher in lieu of "Chinese criterion". However, the impact of other factors on calculation of LPI indices should not be neglected. It should be pointed out that, the computed liquefaction potential based on these studies, is related to a single soil layer and is a function of the corrected clean sand equivalent SPT blow counts $\left(\mathrm{N}_{60}\right)$ or the CPT cone tip resistance of the studied layer and also the cyclic stress ratio. Thus, a comparison among these expressions by simply judging LPI ranges is inappropriate due to the fact that the dependent variables of each equation are different. That is why LPI index still is not a comprehensive measure to quantify liquefaction potential and, in any study, influential conditions on measuring LPI index should be first determined properly or otherwise, be accompanied by a coupled survey so that a practical application for LPI index would be possible.

\section{RESULTS}

Incorporating available in-situ tests such as SPT and CPT data in conjunction with one another is one of the advanced methods for utilizing liquefaction potential indices such as LPI index. So far, according to Table. 1 , researchers tend to quantify liquefaction potential by employing separate means of SPT or CPT because of the complexity of coupled analyses. But it is gradually becoming a favorable procedure that with employment of geological mapping and corresponding visualization of each SPT and CPT profile on that, the liquefaction potential index (LPI) could be calculated as a function of seismic demand, and afterwards the results are grouped based on surface geology [30]. This method for analyzing liquefaction potential by incorporating LPI index returns the probability of moderate and major liquefaction in each geological unit as a function of earthquake magnitude and rate of occurrence and then by assigning a specific color and relative intensity to each point, severity of liquefaction potential is demonstrated. Subsequently, liquefaction hazard maps are prepared accordingly for different scenario earthquake and expected ground motions (PGA) in each study area.

However, development of liquefaction geologic-hazard maps involves the employment of additional geological and geotechnical maps as inputs too. The two common inputs are (1) depth to the top of sedimentary deposits mainly layers with saturated clean sands to silty sands layers and (2) average shear wave velocity in the top susceptible strata and site-adjusted peak ground surface acceleration. In that regard, (Figure 7), represents a common procedure of incorporating both SPT and CPT data analysis on a geology map of Memphis/Shelby County, USA, implemented by a researcher as one of the best methods for visualizing liquefaction potential [31]. They developed liquefaction geologic-hazard map in reference to Iwasaki criterion by assigning $\mathrm{LPI}>5$ as the minor and LPI $>15$ as the major indicators of liquefaction risk severity, respectively. As can be seen from (Figure 8), after a joint analysis of information about SPT and CPT belonging to each data point and then by computing the values of CSR and CRR considering tip resistance and $\mathrm{N}_{60}$, the factor of safety is defined according to Eq. (5) [32].

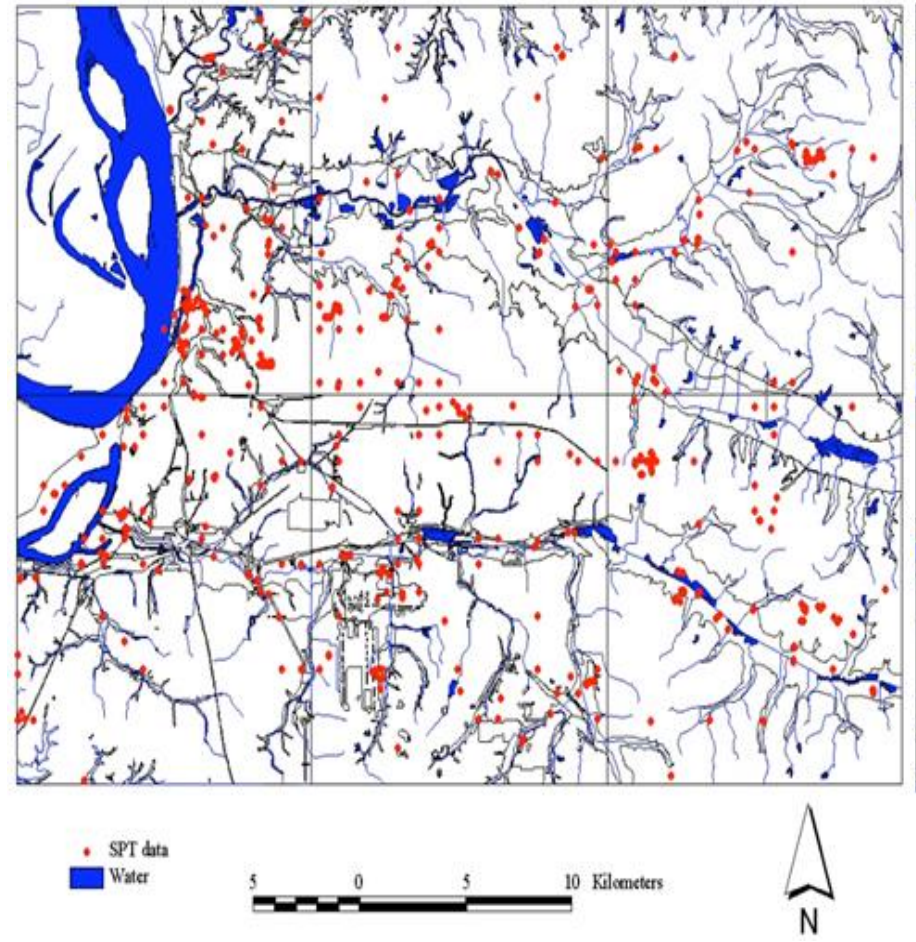

(a)

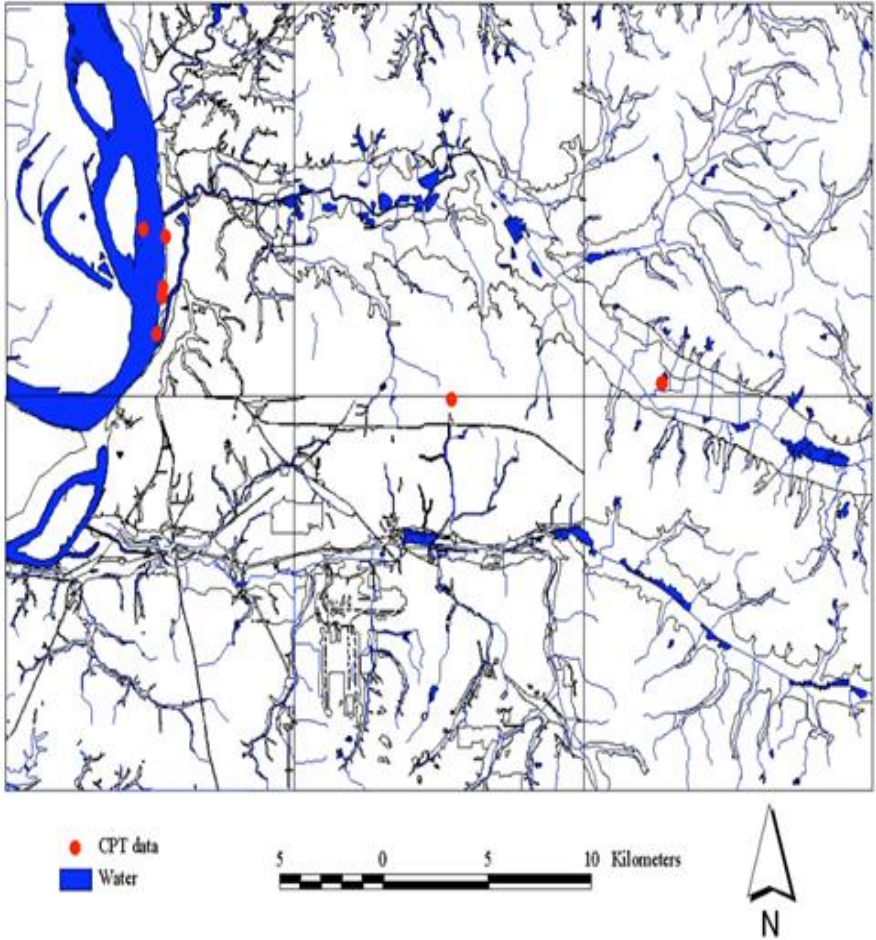

(b)

Figure 7: Location of (a) SPT and (b) CPT profiles on geological map after Rix and Hudock [34]

Consequently, the probability of liquefaction occurrence is defined as a cofunction of peak ground motion and as shown in (Figure 8), the colored regions with deeper intensity are representing the higher liquefaction potential. It is worth mentioning that as shown in (Figure $8 \mathrm{a}$ and $\mathrm{b}$ ) those areas near to river intake with alluvial deposits are the more vulnerable sites to liquefaction. Then, in order to visualize taken measures to provide enough resources for mapping of liquefaction potential (Figure 9) including general order of application of each related test is presented as a flowchart tool. As can be seen in (Figure 9), almost all geotechnical tests are essential to draw liquefaction geologic-hazard map and this fact indicates that an interdisciplinary instrumentation of all engineering skills is required for making a reliable hazard map [33]. Investigated literature showed that there is yet no reliable procedure which can be ascertained from obtained data by SPT and CPT tests. Besides that, current practice of liquefaction assessment is profoundly dependent on empirical investigations which are varying from a place to another one. Geological hazard maps commonly represent the surficial characteristics of the studied areas while SPT and particularly CPT logs represent soil depth profiling with numerous parameters [34]. As LPI index is mainly dependent on soil's physical indices, it is highly recommended that a more multivariate index to be used for mapping liquefaction hazard with consideration of variation of soil strata's characteristics not only buy performing in-situ tests such as CPT which identified tip resistance and sleeve friction of soil but also by performing equivalent tests in the laboratory such as triaxial cyclic or monotonic shearing which is capable of verifying the obtained result by providing the cohesion degree and soil's grain internal friction angle in a way that a high confidence is reachable between in-situ and in-laboratory result in prediction of the liquefaction potential. 

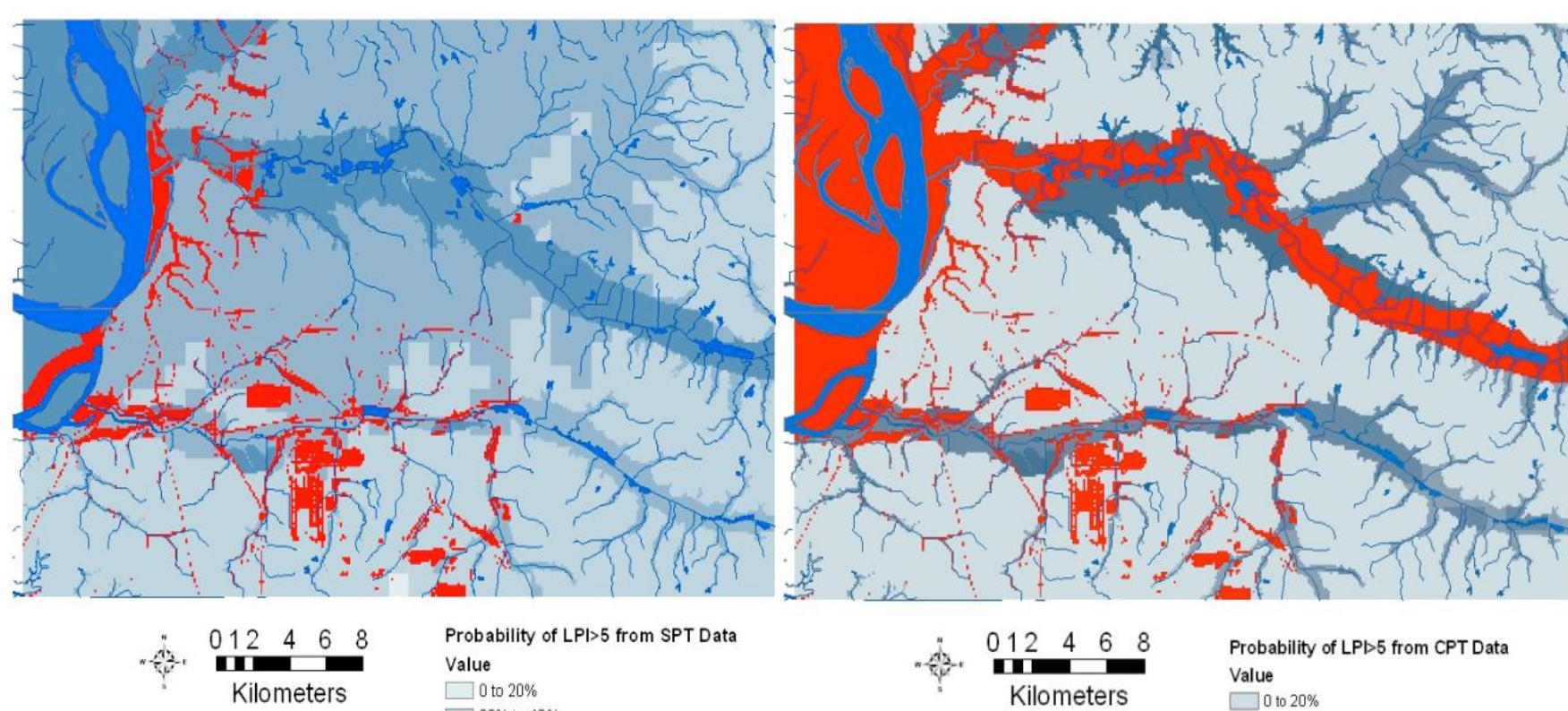

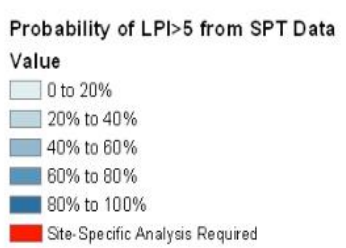

(a)

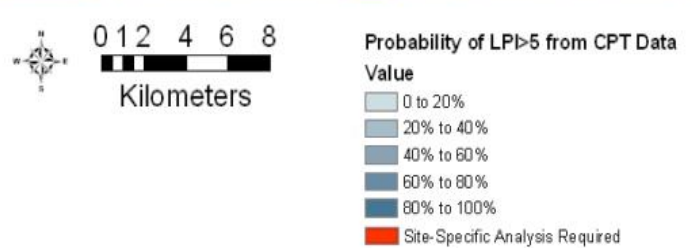

(b)

Figure 8: Probability of Liquefaction after Rix and Hudock [34] study, due to a Mw = 7.7 Earthquake from (a) SPT and (b) CPT data

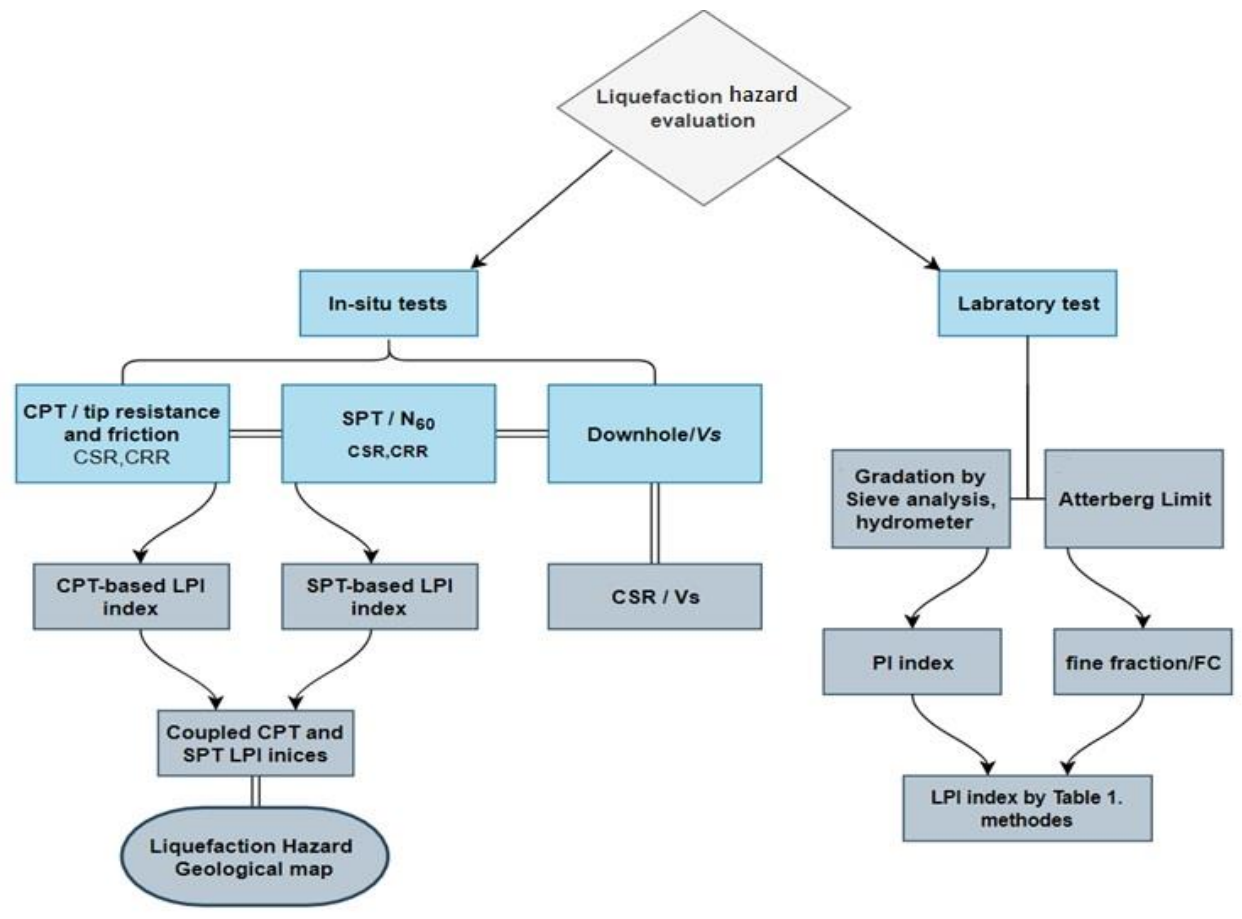

Figure 9: Flowchart of liquefaction hazard map instrumentation

\section{CONCLUSION}

Based on the extensive literature review of the most common liquefaction potential measurements such as evaluations done by physical engineering indices and in-situ tests such as Downhole based shear wave velocity, SPT, $\mathrm{CPT}$ and $\mathrm{CPTu}$, it is concluded that:

As influential factors controlling liquefaction potential are soil and earthquake-related structural elements, no practical method or testing procedure yet exists for incorporating all these factors to develop a reliable criterion. Additionally, employment of a certain method without considering other measures will lead to catastrophic consequences such in cases of Koeceli earthquake and Chi-Chi earthquake where modified Chinese criterion previously determined those area as a safe zone. This is an awakening sign that soil's physical property related criteria such as modified Chinese criterion and its depended criteria such as Iwasaki criterion are not fully reliable any more.

Furthermore, SPT and CPT resultant criteria are generally preferred because of more extensive databases and reliable outputs. Additionally, it is demonstrated that as much sophisticated and undisturbed testing procedure is; results will be more reliable. Accordingly, CPTu test and its criteria for liquefaction hazard assessment such as Eslami and Fellenius chart or Robertson charts are more reliable, because they contain all the principles of an ordinary CPT test while promoting the results by considering the pore water pressure. Likewise, comparing Downhole test's less disturbance in soil with CPTu's induced disturbance, for what is worth, available criterion to assess liquefaction potential by means of CPT related tests are way reliable than those belonging to Downhole tests. 
Additionally, in respect to in-situ tests, it was shown that an individual interpretation of each SPT and CPT data cannot guarantee a reliable index for characterizing liquefaction potential and that is why coupled analyses of SPT and CPT tests based on LPI index, are now gaining favor in practice. Finally, it was concluded that the best way to visualize probability of liquefaction occurrence is by utilizing LPI index with incorporation of liquefaction geologic-hazard map of studied area which this certainly help practitioners to simply locate vulnerable areas for further urban planning.

\section{ACKNOWLEDGMENT}

The authors would like to greatly appreciate Dr. Glenn J. Rix of Georgia Institute of Technology, USA, for providing his published paper as a reference in this study.

\section{REFERENCES}

[1] Youd, T.L., Idriss, I.M. 2001. Liquefaction resistance of soils: summary report from the 1996 NCEER and 1998 NCEER/NSF workshops on evaluation of liquefaction resistance of soils. Journal of geotechnical and geoenvironmental engineering, 127(4), 297-313.

[2] Bray, J.D., Sancio, R.B. Assessment of the liquefaction susceptibility of fine-grained soils. Journal of geotechnical and geoenvironmental engineering, 132(9): 1165-1177

[3] Seed, R.B., Cetin, K.O., Moss, R.E., Kammerer, A.M., Wu, J., Pestana, J.M., Faris, A. 2003. Recent advances in soil liquefaction engineering: a unified and consistent framework. In Proceedings of the 26th Annual ASCE Los Angeles Geotechnical Spring Seminar: Long Beach, CA.

[4] Boulanger, R.W., Idriss, I.M. 2006. Liquefaction susceptibility criteria for silts and clays. Journal of geotechnical and geoenvironmental engineering, 132(11), 1413-1426.

[5] Rahman, M.Z., Siddiqua, S., Kamal, A.M. 2015. Liquefaction hazard mapping by liquefaction potential index for Dhaka City, Bangladesh. Engineering geology, 188, 137-147.

[6] Maurer, B.W., Green, R.A., Cubrinovski, M., Bradley, B.A. 2015. Assessment of CPT-based methods for liquefaction evaluation in a liquefaction potential index (LPI) framework.

[7] Guo, T., Prakash, S. 2000. Liquefaction of silt-clay mixtures. In Proc., 12th World Conf. on Earthquake Engineering. NZ Soc. for EQ Engrg.

[8] Wang, W.S. 1980. Strength, liquefaction and failure of saturated sands under cyclic loading. J Hydraul Eng, 1, 14-27.

[9] Andrews, D.C., Martin, G.R. 2000. Criteria for liquefaction of silty soils. In Proc., 12th World Conf. on Earthquake Engineering. Upper Hutt, New Zealand: NZ Soc. for EQ Engrg.

[10] Seed, H., Idriss, I. 1982. Ground motions and soil liquefaction during earthquakes: engineering monographs on earthquake criteria, structural design, and strong motion records. MNO-5. Earthquake Engineering Research Institute, Oakland, Calif.

[11] Polito, C.P., Martin II, J.R. 2001. Effects of nonplastic fines on the liquefaction resistance of sands. Journal of Geotechnical and Geoenvironmental Engineering, 127(5), 408-415.

[12] Law, K. T., Ling, Y.H. 1992. Liquefaction of granular soils with noncohesive and cohesive fines. In Proceedings of the tenth world conference on earthquake engineering, 1491-1496.

[13] Seed, H.B., Idriss, I.M. 1971. Simplified procedure for evaluating soil liquefaction potential. Journal of Soil Mechanics \& Foundations Div.

[14] Gilstrap, S.D. 1998. CPT based liquefaction resistance analyses evaluated using case histories (Doctoral dissertation, Department of Civil and Environmental Engineering, Brigham Young University).

[15] Robertson, P.K., Wride, C.E. 1998. Evaluating cyclic liquefaction potential using the cone penetration test. Canadian Geotechnical Journal, 35(3), 442-459.
[16] Li, K., Liang, W., Cai, G., Liu, S., Du, Y., Zhu, L. 2018. Evaluation of Engineering Characteristics of South China Sea Sedimentary Soil in Sanya New Airport Based on CPTU Data. In Proceedings of China-Europe Conference on Geotechnical Engineering (pp. 699-702). Springer, Cham.

[17] Robertson, P.K. 2009. Evaluation of flow liquefaction and liquefied strength using the cone penetration test. Journal of Geotechnical and Geoenvironmental Engineering, 136(6), 842-853.

[18] Boulanger, R.W., Idriss, I.M. 2015. CPT-based liquefaction triggering procedure. Journal of Geotechnical and Geoenvironmental Engineering, 142(2), 04015065.

[19] Eslami, A.A., Fellenius, B.H. 2004. CPT and CPTu data for soil profile interpretation: review of methods and a proposed new approach.

[20] Ahmadi, M.M., Eslami, A., Kangarani, M.R. 2009. Liquefaction evaluation based on CPTu soil classification chart. In Proceedings of the 17th International Conference on Soil Mechanics and Geotechnical Engineering: The Academia and Practice of Geotechnical Engineering, Alexandria, Egypt, 5-9 October 2009, Volume 2 (pp. 1028-1031). IOS Press.

[21] Elgamal, A., Lai, T., Yang, Z., He, L. 2001. Dynamic soil properties, seismic Downhole arrays and applications in practice.

[22] Ishihara, K. 1996. Soil behavior in earthquake geotechnics. Oxford engineering science series.

[23] Andrus, R.D., Stokoe II, K.H. 2000. Liquefaction resistance of soils from shear-wave velocity. Journal of geotechnical and geoenvironmental engineering, 126(11), 1015-1025.

[24] Andrus, R.D., Stokoe, K.H., Hsein Juang, C. 2004. Guide for shearwave-based liquefaction potential evaluation. Earthquake Spectra, 20(2), 285-308.

[25] Liao, S.S., Whitman, R.V. 1986. Overburden correction factors for SPT in sand. Journal of geotechnical engineering, 112(3), 373-377.

[26] Stokoe, K.H., Li, S.C., Cox, B.R., Menq, F.Y., Rohay, A.C. 2008. Deep Downhole Seismic Testing for Earthquake Engineering Studies (No. PNNLSA-62393). Pacific Northwest National Lab. (PNNL), Richland, WA (United States).

[27] Idriss, I.M. 1997. Evaluation of liquefaction potential and consequences: Historical perspective and updated procedures. Proc., 3rd Seismic Short Course on Evaluation and Mitigation of Earthquake Induced Liquefaction Hazards.

[28] Iwasaki, T. 1978. A practical method for assessing soil liquefaction potential based on case studies at various sites in Japan. In Proc. Second Int. Conf. Microzonation Safer Construction Research Application, 2, 885896.

[29] Maurer, B.W., Green, R.A., Cubrinovski, M., Bradley, B.A. 2014. Evaluation of the liquefaction potential index for assessing liquefaction hazard in Christchurch, New Zealand. Journal of Geotechnical and Geoenvironmental Engineering, 140(7), 04014032.

[30] Townsend, D., Lee, J.M., Strong, D.T., Jongens, R., Smith Lyttle, B., Ashraf, S., Taylor, M.L. 2016. Mapping surface liquefaction caused by the September 2010 and February 2011 Canterbury earthquakes: A digital dataset. New Zealand Journal of Geology and Geophysics, 59(4), 496-513.

[31] Toprak, S., Holzer, T.L. 2003. Liquefaction potential index: field assessment. Journal of Geotechnical and Geoenvironmental Engineering, 129(4), 315-322.

[32] Papathanassiou, G. 2008. LPI-based approach for calibrating the severity of liquefaction-induced failures and for assessing the probability of liquefaction surface evidence. Engineering Geology, 96(1-2), 94-104.

[33] Lee, D.H., Ku, C.S., Yuan, H. 2004. A study of the liquefaction risk potential at Yuanlin, Taiwan. Engineering Geology, 71(1-2), 97-117.

[34] Rix, G.J., Romero-Hudock, S. 2006. Liquefaction potential mapping in Memphis and Shelby County, Tennessee. Engineering Geology, 27. weak $\operatorname{rock}(\mathrm{Q}<1)$. 